\title{
Partial Volume Prediction Through Nonlinear Mixed Modeling
}

\section{Marcos Felipe Nicoletti ${ }^{1}$ (D), Samuel de Pádua Chaves e Carvalho ${ }^{2}$ (1), Sebastião do Amaral Machado ${ }^{3}$ (D), Afonso Figueiredo Filho ${ }^{4}$ (D), Gustavo Silva Oliveira ${ }^{3}$}

\author{
${ }^{1}$ Universidade do Estado de Santa Catarina (Udesc), Lages, SC, Brasil \\ ${ }^{2}$ Universidade Federal de Mato Grosso (UFMT), Cuiabá, MT, Brasil \\ ${ }^{3}$ Universidade Federal do Paraná (UFPR), Curitiba, PR, Brasil \\ ${ }^{4}$ Universidade Estadual do Centro-Oeste (Unicentro), Irati, PR, Brasil
}

\begin{abstract}
The objective of this study was to assess the prediction of partial volumes with nonlinear mixed modeling for Pinus taeda. The volume of 558 trees was measured. The four-parameter logistic model was used in its modified form for the nonlinear mixed approach and, for comparison, the $5^{\text {th }}$ degree polynomial was used. In the mixed modeling, the random effects diameter, age and place were inserted. The statistical criteria used to assess the quality of the adjustment were the Akaike Information Criterion (AIC), the Bayesian Information Criterion (BIC), standard error of the estimate (Syx) and residual graphical analysis. Among the random effects analyzed, age obtained the best adjustment. However, to predict partial volumes, it was noticed that, regardless of the analyzed portion of the trunk, the $5^{\text {th }}$ degree polynomial had the best estimates, with a mean standard error of $20.1 \%$ of the estimate compared to $51.8 \%$ of the logistic.
\end{abstract}

Keywords: forest biometrics, logistic model, taper. 


\section{INTRODUCTION}

To know the tapering of tree shafts is important for planning and implementing forest activities, especially when one wants to classify the production through the wooden logs. By associating it with the growth factor, the mathematical description of the tapering allows to dynamically infer the quantity and dimension of the logs, simulating scenarios that contribute to studies on the economic viability of the forest (Costa et al., 2016). Simulations of different scenarios are possible through application of linear and nonlinear modeling techniques. Thus, it is possible to quantify the multiple products from the settlements.

In this context, nonlinear models are preferable to describe biological phenomena, since they usually provide more precise estimates when compared to linear models. Besides, for some specific cases, this accuracy in the estimate is also associated to direct interpretation of the parameters, linked to the flexibility of application that they provide (Santos, 1996). Some authors, such as Mendonça et al. (2007), Pires \& Calegario (2007) and Horle et al. (2010) verified the superiority of nonlinear models regarding linear ones in the modeling of tree profiles.

A prediction model usually needs a large and representative data set, addressing different characteristics for the construction and adjustment stages. Therefore, traditional models with only fixed coefficients do not consider the possible variation of parameters between different groups. Thus, mixed models can deal with this variation, considering some model parameters to be random (Pinheiro \& Bates, 2000). Given this context, forest science already has major contributions in this topic, such as Calegario (2002) and Calegario et al. (2005) on de modeling of growth and forest production of Eucalyptus sp.; Trincado et al. (2007), Meng et al. (2008) and Mendonça et al. (2015) in the description of the hypsometric relation; Vismara et al. (2016) in volume prediction; and Carvalho et al. (2014), Arias-Rodil et al. $(2015,2016)$ and Môra (2015) in the tapering modeling.

Therefore, with the advances in computing and biometric techniques, estimates can be obtained more accurately and more rapidly by generating the parameters of the models. Given this, the objective was to assess and compare the estimates of the partial volumes of
Pinus taeda obtained by the nonlinear mixed modeling compared to the traditional one.

\section{MATERIAL AND METHODS}

\subsection{Area of study}

The study was performed in the municipality of Campo Belo do Sul-SC, in the region of the company Florestal Gateados Ltda. The place is circumscribed by the following geographical coordinates: S28 $03^{\prime} 26^{\prime \prime}$ W50 $46^{\prime} 13^{\prime \prime}$. According to Koppen's classification, the climate in the study area is predominantly $\mathrm{Cfb}$, mesothermal, humid subtropical, with cool summers, without defined dry seasons, with occurrence of severe frosts and average annual temperature of $16^{\circ} \mathrm{C}$. Annual precipitation varies from 1,300 to $2,400 \mathrm{~mm}$ and the average altitude is $950 \mathrm{~m}$. The most representative soil in the place is Haplic Nitisol, with associations of Cambisol and Litholic Neosol in the sloping areas (Embrapa, 1988).

\subsection{Data collection}

The dendrometric variables for behavioral analysis of the trunk profile are distributed in a data set of 558 Pinus taeda trees in four forest sites provided by the company, ranging from 11 to 31 years-old.

The measured trees were selected based on the diametric distribution of the settlements from the forest inventory data. These selected individuals were felled and cut and their diameters were measured at different heights along the trunk at $0.1 \mathrm{~m} ; 0.3 \mathrm{~m} ; 0.5 \mathrm{~m} ; 0.9 \mathrm{~m}$; $1.3 \mathrm{~m} ; 2 \mathrm{~m}$ and from $2 \mathrm{~m}$ it was measured from meter to meter up to the minimum diameter of $5 \mathrm{~cm}$. The diameter of the logs was measured with a bevel gauge, and lengths with a measuring tape. The individual volume of the trees was determined by Smalian's formula, according to Machado \& Figueiredo Filho (2006). Diameter measurement was used to obtain individual volumes for posterior comparison with the volume predicted by the equations. A statistical summary of the main dendrometric variables of the 558 sampled trees is described in Table 1.

Subsequently, five diametric classes were established through previous analysis by the empirical criterion for tree representation. 
Table 1. Statistical information of diameter at breast height (DBH), total height $(\mathrm{h})$ and individual volume (v) of the Pinus taeda trees.

\begin{tabular}{lccc}
\multicolumn{1}{c}{ Statistics } & DBH $(\mathbf{c m})$ & $\mathbf{h}(\mathbf{m})$ & $\mathbf{v}\left(\mathbf{m}^{3}\right)$ \\
\hline Minimum & 14.9 & 14.1 & 0.1374 \\
Mean & 37.7 & 29.2 & 1.7473 \\
Maximum & 65.0 & 41.5 & 5.4871 \\
$\begin{array}{l}\text { Standard deviation } \\
\begin{array}{l}\text { Coefficient } \\
\text { of variation }\end{array}\end{array}$ & 9.1 & 5.0 & 0.9554 \\
\hline
\end{tabular}

\subsection{Logistic Model}

The use of the logistic function to describe tree tapering was addressed by Calegario (2002) and aims to describe height variations when the diameter also varies (Equation 1). This approach differs from others traditionally used in forest science since (in this case) the diameter variation is the independent variable of the model.

Modified logistic model (Carvalho et al., 2014):

$$
\frac{h_{i j}}{h t_{i}}=\varphi_{1}+\frac{\varphi_{2}-\varphi_{1}}{1+\exp \left[\left(\varphi_{3}-\frac{r_{i j}}{r a p_{i}}\right) / \varphi_{4}\right]}+\varepsilon_{i j}
$$

$h_{i j}$ : height of the i-th tree in the j-th position of the shaft (m); $h t_{i}$ : total height of the $\mathrm{i}$-th tree $(\mathrm{m}) ; r_{i j}$ : radius of the $\mathrm{i}$-th tree in the $\mathrm{j}$-th position of the trunk $(\mathrm{cm})$; rap: radius of the $\mathrm{i}$-th tree measured at breast height $(\mathrm{cm}) ; \varphi_{i}$ : regression of coefficients of fixed and random effects; $\varepsilon_{i j}$ : random error.

$$
\begin{aligned}
& \varphi_{i}=\left[\begin{array}{c}
\varphi_{1 i} \\
\varphi_{2 i} \\
\varphi_{3 i} \\
\varphi_{4 i}
\end{array}\right]=\left[\begin{array}{l}
\beta_{1} \\
\beta_{2} \\
\beta_{3} \\
\beta_{4}
\end{array}\right]+\left[\begin{array}{l}
b_{1 i} \\
b_{2 i} \\
b_{3 i} \\
b_{4 i}
\end{array}\right]=\beta+b_{i} \\
& b_{i} \sim N\left(0, \sigma^{2}\right) ; \varepsilon_{i j} \sim N\left(0, \sigma^{2}\right)
\end{aligned}
$$

The representation of the logistic model is that $\beta$ are fixed effects, $b_{i}$ random effects and $\varepsilon_{i j}$ deviations obtained with the prediction of the model regarding the observed variables. Random effects are assumed as being independent for different situations in modeling and the errors within the groups are assumed as being independent for the different scenarios $\left(\varepsilon_{i j}\right)$. The decomposition of model parameters was performed to insert the random effects of diametric class, age and site. The finality is obtaining parsimonious models of simple interpretation and that increase the accuracy of the predictions. The initial estimates of the parameters were obtained through the SelfStart functions, described by Pinheiro \& Bates (2000) through the nlme packet of the Software R.

\subsection{Fifth degree polynomial (Schöepfer, 1966)}

To compare the obtained estimates with the best mixed logistic model, a traditionally addressed model for tapering functions of tree shafts was used (the $5^{\text {th }}$ degree polynomial), as shown in Equation 2.

$$
\frac{d i}{D B H}=\beta_{0}+\beta_{1}\left(\frac{h i}{h}\right)+\beta_{2}\left(\frac{h i}{h}\right)^{2}+\beta_{3}\left(\frac{h i}{h}\right)^{3}+\beta_{4}\left(\frac{h i}{h}\right)^{4}+\beta_{5}\left(\frac{h i}{h}\right)^{5}+\varepsilon_{i}
$$

$d i$ : estimated diameter (cm); hi: height along the trunk (m); DBH: diameter at breast height (cm); h: total height (m); $\beta_{0^{3}} \beta_{1}, \beta_{2}, \beta_{3}, \beta_{4}$ and $\beta_{5}$ : parameters of the equation to be estimated; $\varepsilon_{i j}$ : error of the estimate.

\subsection{Partial and total volumes}

For the volume of the trees, techniques of integration of the base area on the length of the shaft of solids of revolution were used. These techniques are determined through numerical calculation and generate the volume of solid cylindrical shells. This method to obtain the volume of solid shells involves rotating elements of rectangular area parallel to the axis of revolution (axis y), which generates a solid contained between two cylinders with the same center and axis. Thus, the volume of this solid is obtained by the sum of $n$ rectangular elements. As described by Carvalho et al. (2014), the volume per integration for different radii is obtained with Equation 3 for the modified logistic model. 
$V=\int_{R_{\min }}^{R_{\max }} 2 \pi R_{i}\left\{\left[\varphi_{1}+\frac{\varphi_{2}-\varphi_{1}}{1+\exp \left[\left(\varphi_{3}-\frac{r_{i j}}{r a p_{i}}\right) / \varphi_{4}\right]}\right] \star h_{t}\right\} d R$

$R_{\min }:$ radius in the estimate position of minimum radius; $R_{\max }$ : estimate of the maximum radius; $R_{i}:$ mean radius of the $\mathrm{i}$-th generated cylinder $(\mathrm{m})$; $h t_{i}$ : total height of the $\mathrm{i}$-th tree $(\mathrm{m}) ; r_{i j}$ : radius of the $\mathrm{i}$-th tree in the j-th position of the trunk $(\mathrm{cm})$; rap $_{\mathrm{i}}$ : radius of the $\mathrm{i}$-th tree measured at breast height $(\mathrm{cm}) ; \varphi_{i}$ : regression coefficients; $V$ : volume of the section between minimum and maximum radius, and consequently the individual volume of the tree.

In order to obtain the volume through the $5^{\text {th }}$ degree polynomial, the sectional area of the tree base was integrated between the lower boundary $\left(\mathrm{h}_{1}\right)$ and the upper boundary $\left(\mathrm{h}_{2}\right)$, which is desired to establish as Scolforo (2005) describes in Equation 4.

$v=\int_{h_{1}}^{h_{2}} \frac{\pi}{40000} w^{2} d_{w}$

$v$ : estimated total or partial volume; $h_{1}$ : lower boundary used in the integration process; $h_{2}$ : upper boundary used in the integration process; $w$ : tapering model as a function of the independent variable $d$.

In order to assess the accuracy of the estimates obtained with the tapering functions for partial volumes, the tree trunks were divided in three parts (base, middle and apex). The stratification of the shaft was considered, in the base, from $0.1 \mathrm{~m}$ to $25 \%$ of the total height, in the intermediate portion from $25 \%$ to $75 \%$ of the total height and, in the apex, from $75 \%$ to $95 \%$ of the total height (Môra, 2015). The integration was performed using the integrate function associated to the maply function, both implemented in the Software R. For comparison between the best prediction with the $5^{\text {th }}$ degree polynomial, from the logistic model, only the equation that best adjusted between the three random effects analyzed was selected (diametric class, age and site).

\subsection{Statistical analysis and model accuracy}

To evaluate the proposed models, the Akaike Information Criterion (AIC), the Bayesian Information Criterion (BIC) and the Standard Error of the Estimate $\left(S_{y x}\right)$ were used, described by Carvalho et al. (2014). The smaller their respective values, the better the equation was considered.

The graphs of the existing residuals were also analyzed in the prediction of the models, by the difference between the observed values, obtained in the field, and the estimated ones through the equations. The quality of the adjustment of the equations was also assessed through standardized residual dispersion (Souza, 1998). All the equations had their coefficients analyzed through the t-test, with a $5 \%$ probability level. The analyses were performed by the Software R, version 3.1, using the nlme package developed by José C. Pinheiro and Douglas Bates (R Development Core Team, 2015).

\section{RESULTS AND DISCUSSION}

With the use of the theory of mixed models, the fixed and random parameters were estimated by age (Table 2), diametric class (Table 3) and site (Table 4) for the modified logistic model. The significance of the equations was verified in it through the t-test in all the analyzed coefficients, both with fixed and random effects. In the traditional approach, the coefficients were estimated with the $5^{\text {th }}$ degree polynomial (Table 5).

In general, in Tables 2, 3 and 4 a small variation is noticed between the parameters of regression. This, in greater magnitude, can contribute to large differences in the prediction process of the settlement assortments.

The statistics of the modified logistic model with the decomposition of the parameters by random effects are shown in Table 6.

There was no representative distinction between the mixed models for the analyzed statistical criteria. The logistic models demonstrated better adjustments in relation to the 5th degree polynomial for AIC and BIC. For these two statistical criteria used, models with random effects obtained greater accuracy. The logistic model with the random effect age was considered the one with best adjustment in general and, therefore, it was selected for comparison with the $5^{\text {th }}$ degree polynomial. However, for the standard error of the height estimate (hi), 
Table 2. Fixed and random parameters of the modified logistic model by age.

\begin{tabular}{|c|c|c|c|c|c|c|c|c|}
\hline \multirow{2}{*}{ Age } & \multicolumn{2}{|c|}{$\varphi 1$} & \multicolumn{2}{|c|}{$\varphi 2$} & \multicolumn{2}{|c|}{$\varphi 3$} & \multicolumn{2}{|c|}{$\varphi 4$} \\
\hline & Fixed & Random & Fixed & Random & Fixed & Random & Fixed & Random \\
\hline 11 & \multirow{13}{*}{0.8546} & 0.8400 & \multirow{13}{*}{-0.0667} & -0.0618 & \multirow{13}{*}{0.7637} & 0.7372 & \multirow{13}{*}{0.1459} & 0.1647 \\
\hline 12 & & 0.8141 & & -0.0504 & & 0.7589 & & 0.1545 \\
\hline 13 & & 0.8562 & & -0.0749 & & 0.7617 & & 0.165 \\
\hline 19 & & 0.8264 & & -0.1047 & & 0.8142 & & 0.1527 \\
\hline 21 & & 0.8355 & & -0.0696 & & 0.762 & & 0.1453 \\
\hline 23 & & 0.8955 & & -0.0724 & & 0.7386 & & 0.1509 \\
\hline 24 & & 0.8582 & & -0.0644 & & 0.7513 & & 0.142 \\
\hline 25 & & 0.8721 & & -0.0633 & & 0.7496 & & 0.1484 \\
\hline 26 & & 0.8425 & & -0.0629 & & 0.7775 & & 0.1402 \\
\hline 27 & & 0.8606 & & -0.0606 & & 0.7716 & & 0.1313 \\
\hline 28 & & 0.8727 & & -0.0654 & & 0.7663 & & 0.1351 \\
\hline 30 & & 0.8823 & & -0.0731 & & 0.7721 & & 0.141 \\
\hline 31 & & 0.8634 & & -0.0712 & & 0.7737 & & 0.1366 \\
\hline
\end{tabular}

Table 3. Fixed and random parameters of the modified logistic models by diametric class.

\begin{tabular}{|c|c|c|c|c|c|c|c|c|}
\hline \multirow{2}{*}{ Class } & \multicolumn{2}{|c|}{$\varphi 1$} & \multicolumn{2}{|c|}{$\varphi 2$} & \multicolumn{2}{|c|}{$\varphi 3$} & \multicolumn{2}{|c|}{$\varphi 4$} \\
\hline & Fixed & Random & Fixed & Random & Fixed & Random & Fixed & Random \\
\hline 20 & \multirow{5}{*}{0.8647} & 0.8454 & \multirow{5}{*}{-0.0696} & -0.0608 & \multirow{5}{*}{0.7578} & 0.7503 & \multirow{5}{*}{0.1492} & 0.1615 \\
\hline 30 & & 0.8511 & & -0.0647 & & 0.7759 & & 0.1432 \\
\hline 40 & & 0.8732 & & -0.0694 & & 0.7559 & & 0.1446 \\
\hline 50 & & 0.8713 & & -0.0758 & & 0.7616 & & 0.1457 \\
\hline 60 & & 0.8866 & & -0.0958 & & 0.7502 & & 0.1563 \\
\hline
\end{tabular}

Table 4. Fixed and random parameters of modified logistic model by site.

\begin{tabular}{|c|c|c|c|c|c|c|c|c|}
\hline \multirow{2}{*}{ Site } & \multicolumn{2}{|c|}{$\varphi 1$} & \multicolumn{2}{|c|}{$\varphi 2$} & \multicolumn{2}{|c|}{$\varphi 3$} & \multicolumn{2}{|c|}{$\varphi 4$} \\
\hline & Fixed & Random & Fixed & Random & Fixed & Random & Fixed & Random \\
\hline I & \multirow{4}{*}{0.8661} & 0.8810 & \multirow{4}{*}{-0.0678} & -0.0693 & \multirow{4}{*}{0.7642} & 0.7465 & \multirow{4}{*}{0.1431} & 0.1525 \\
\hline II & & 0.8578 & & -0.0673 & & 0.7685 & & 0.1421 \\
\hline III & & 0.8718 & & -0.0663 & & 0.7686 & & 0.1369 \\
\hline IV & & 0.8313 & & -0.0465 & & 0.7839 & & 0.1421 \\
\hline
\end{tabular}

Table 5. Coefficients and statistics obtained in the adjustment of the $5^{\text {th }}$ degree polynomials.

\begin{tabular}{ccccc} 
Parameter & Estimate & Standard error & t value & $\operatorname{Pr}(>|\mathbf{t}|)$ \\
\hline$\beta_{0}$ & 1.1672 & 0.001547 & 754.7 & \\
$\beta_{1}$ & -3.7173 & 0.041981 & -88.5 & \\
$\beta_{2}$ & 16.7508 & 0.303712 & 55.1 & $<0.0001$ \\
$\beta_{3}$ & -36.3726 & 0.857805 & -42.4 & \\
$\beta_{4}$ & 34.5127 & 1.035597 & 33.3 & \\
$\beta_{5}$ & -12.3560 & 0.448053 & -27.6 & \\
\hline
\end{tabular}


Table 6. Statistical criteria of the tapering equations of Pinus taeda.

\begin{tabular}{|c|c|c|c|}
\hline Model & AIC & BIC & Syx (\%) \\
\hline Logistic - Site & $-41,169.66$ & $-41,055.52$ & 15.0 \\
\hline Logistic - Age & $-42,281.13$ & $-42,166.99$ & 14.5 \\
\hline Logistic - Diametric Class & $-41,225.65$ & $-41,111.57$ & 14.8 \\
\hline $5^{\text {th }}$ degree polynomial & 63,634 & 63,398 & 1,7 \\
\hline
\end{tabular}

In which: AIC is the Akaike Information Criterion; BIC is the Bayesian Information Criterion; and Syx is the residual standard error.

one can notice the great improvement that the $5^{\text {th }}$ degree polynomial provided to the estimates. Pires \& Calegario (2007) studied the shaft profile of Eucalyptus through the logistic model and observed standard error values in this range in different categories of diametric classes.

Mixed models were also evaluated through the graphic analysis of the standardized residue for the modeling with random effects age (Figure $1-\mathrm{A}$ ), diametric class (Figure $1-\mathrm{N}$ ) and site (Figure 1-C) on the hi/ht ratio of the estimated height variable.

The residual distribution found in Figure 1 indicates in general that the residuals in different ages, diametric classes and sites show a similarity between themselves. Through them, it is possible to infer the hypothesis of

(A)

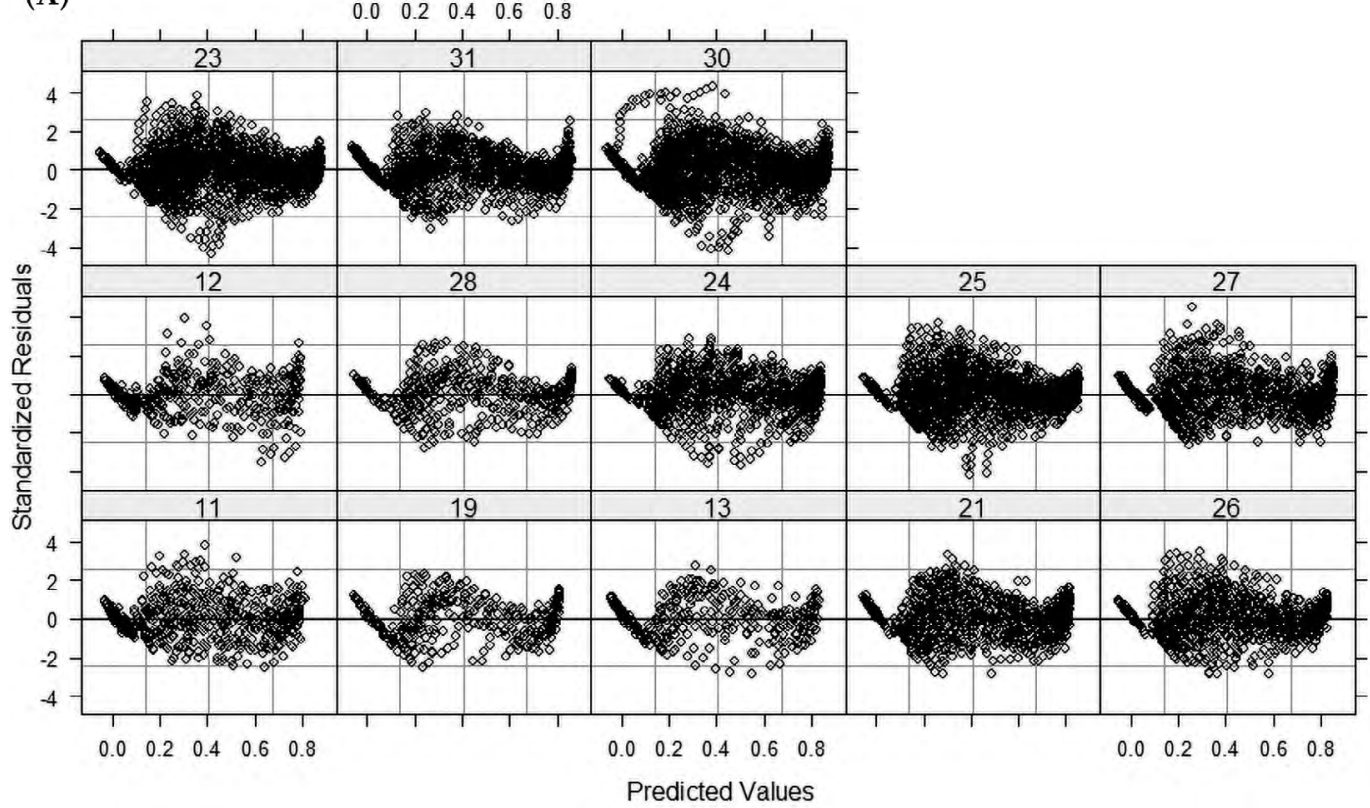

(B)

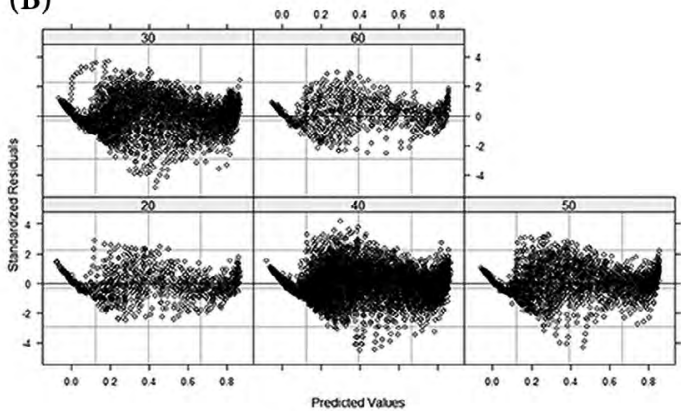

(C)

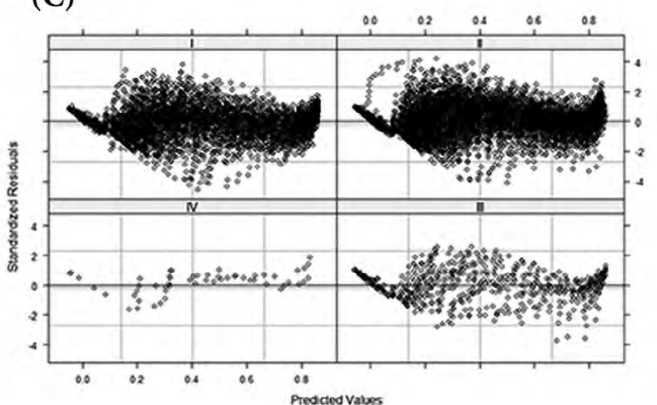

Figure 1. Standardized residues of the mixed modified logistic model with random effects age (a), diametric class (b) and site (c) regarding hi/ht of the estimated height variable. 
normality of the data. Thus, because no distribution showed accentuated asymmetry, these can be considered of normal distribution. An important factor is that the data should be distributed next to the zero axis and preferably forming a horizontal square. Again, in this evaluation, these residuals show this aspect. It can be also said that the greater distribution of the residuals in the predictions of the tree shafts, regardless of the random effect, is found in the median region of the trunk. This is noticeable because the greater randomness and values, more distant from the zero axis there are in this portion. Another observation on the model is that it shows a good distribution in the base of the trunk, in which the hi/ht ratio is smaller. Equations with a better residual distribution in the base are preferable, since it is precisely in this point of the tree trunk that logs of higher added value are. Pires \& Calegario (2007) analyzed the shaft profile for logistic models and also found for the tree bases a smaller randomness of residuals. On the other hand, Horle et al. (2010) found trends of super-estimates for the base of the trunk with the $5^{\text {th }}$ degree polynomial and of the logistic model to describe the profile of Pinus oocarpa. An alternative that could possibly improve these results, and consequently the distribution of residues, would be inserting the effect of their spatial correlation in the modeling.

The residues for the diametric classes in Figure 1 (B) of 20 and $60 \mathrm{~cm}$ were those with a more homogeneous distribution. Thus, some outliers were present, especially in diameter classes of 30,40 and $50 \mathrm{~cm}$. These influence points were remarkable in the initial and median portion of the trunk. Testing the adjustment of the modified logistic model for the tapering of the trunk of Eucalyptus and dividing them in diametric classes, Pires \& Calegario (2007) also verified that this model was superior in the distribution of residues. These authors proved that between linear and non-linear models the logistic one is recommended, since it shows desirable characteristics, such as parameter interpretation, parsimony and data extrapolation. Mendonça et al. (2014) verified the same behavior of the logistic model to predict settlements assortment of eucalyptus.

The adjustment statistics of the partial volume in the three shaft portions for the two evaluated models are found in Table 7. From this point, only the logistic function with the random effect age was analyzed, since it obtained the best adjustment between the studied effects.

Through the standard error of the estimates of the partial volumes of the trunk (Table 7), it is noticeable that, regardless of the analyzed portion, the best estimates were produced by the $5^{\text {th }}$ degree polynomial. When verifying this result, the mean standard error of the estimates was analyzed between the portions of the trunk; the $5^{\text {th }}$ degree polynomial obtained $20.1 \%$, and the logistic $51.8 \%$. The $5^{\text {th }}$ degree polynomial was also considered one of the most accurate by Môra (2015) in the estimates of different portions of the trunk volume for Pinus taeda. However, the errors $\left(\mathrm{S}_{\mathrm{yx}}\right)$ found by this author were less accurate than those observed in this study: $10.8 \%$ for the base portion, $20.3 \%$ for the intermediate portion, and $51.3 \%$ for the final phase of the trunk. As for Souza et al. (2012), they analyzed the total volume estimates for Pinus taeda and found $\mathrm{S}_{\mathrm{yx}}$ values smaller than $6 \%$ for the equation of the $5^{\text {th }}$ degree polynomial. Téo et al. (2013) assessed the same model of Pinus elliottii of different ages for the total volume estimates and found errors from $11 \%$ to $20.7 \%\left(\mathrm{~S}_{\mathrm{yx}}\right)$.

Residuals of partial volume estimates from 0.1 meter to $25 \%$ of the total height, of the intermediate portion volume from $25 \%$ to $75 \%$ of the total height, and from the final portion volume from $75 \%$ to $95 \%$ of the total height are shown in Figure 2.

For the residual produced by volume estimates in the three portions of the tree trunk, the $5^{\text {th }}$ degree polynomial

Table 7. Statistics of the evaluated equations for the partial volume from 0.1 meter to $25 \%$ of the total height $s_{\mathrm{yx} \text {-base }}$ (\%), for the partial volume from $25 \%$ to $75 \%$ of the total height $\mathrm{s}_{\mathrm{yx}-\mathrm{middle}}(\%)$ and for the partial volume from $75 \%$ to $95 \%$ of the total height $\mathrm{s}_{\mathrm{yx}-\mathrm{apex}}(\%)$.

\begin{tabular}{|lccc}
\multicolumn{1}{c}{ Model } & $\mathbf{S}_{y x-b a s e}(\%)$ & $\mathbf{S}_{y x-\text { middle }}(\%)$ & $\mathbf{S}_{y x-a p e x}(\%)$ \\
\hline $5^{\text {th }}$ Degree Polynomial & 7.9 & 13.7 & 38.7 \\
\hline Mixed Modified Logistic - Age & 57.2 & 59.5 & 38.9 \\
\hline
\end{tabular}

In which: Syx (\%) is the standard error of the estimates. 
(A)

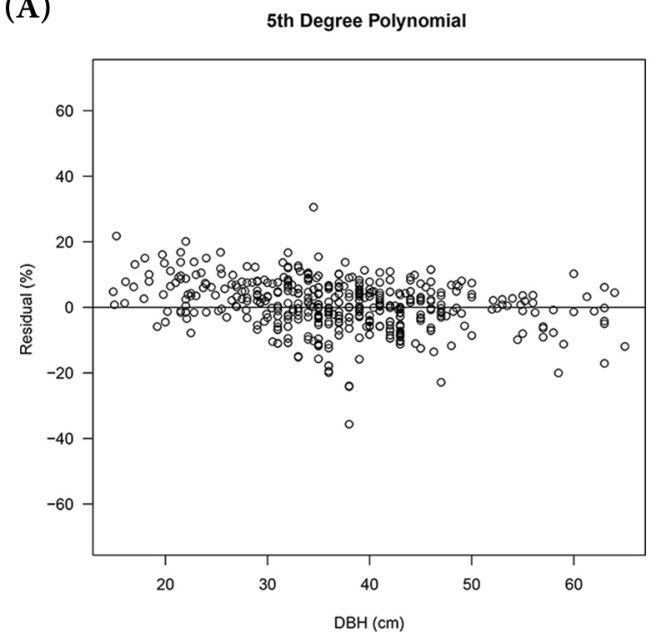

(B)

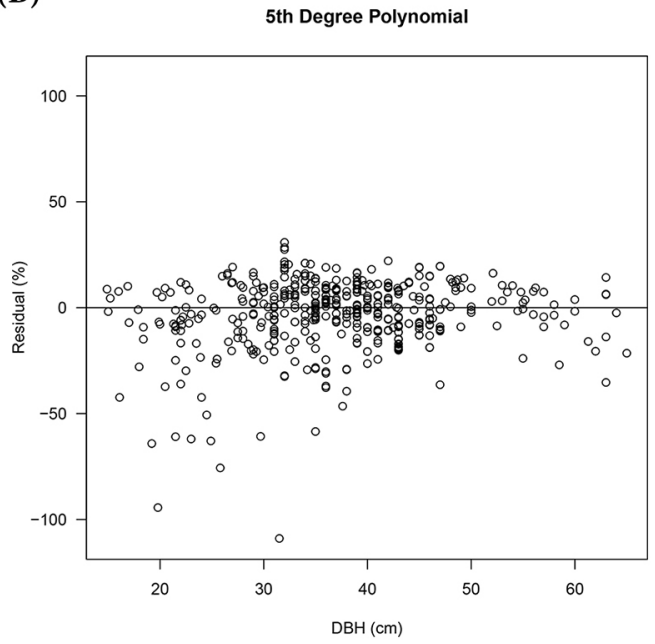

(C)

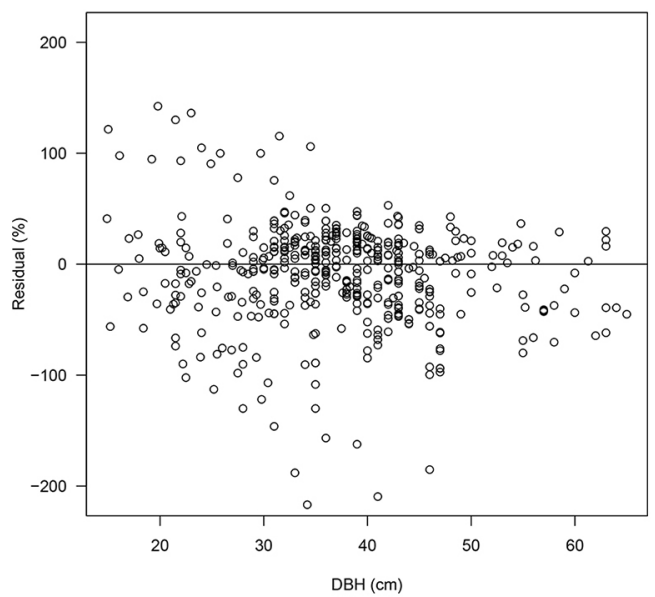

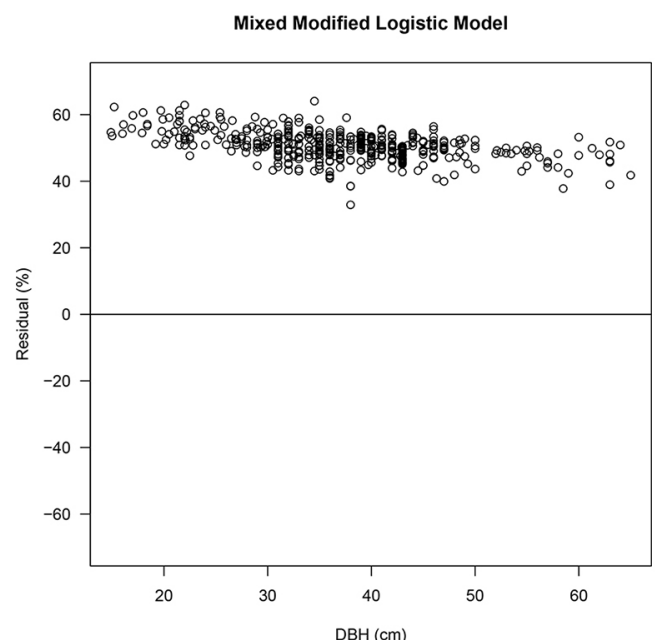
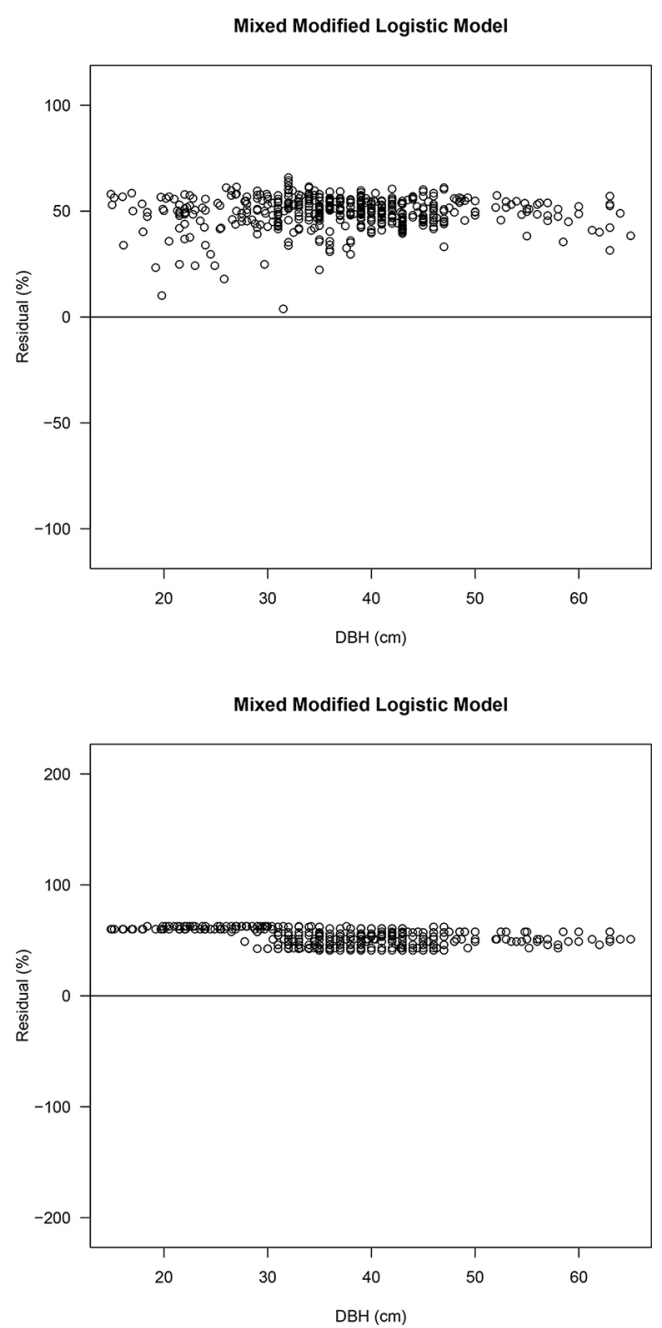

Figure 2. Residuals of the estimates obtained from the estimated partial volume from 0.1 meter to $25 \%$ of the total height (A), from $25 \%$ to $75 \%$ of the total height (B), from $75 \%$ to $95 \%$ of the total height (C) for the $5^{\text {th }}$ degree polynomial and the mixed modified logistic model as a function of the diameter at breast height (DBH). 
showed the best adjustment again. With graphic analysis, the results obtained in Table 7 are verified, in which the greater accuracy is located in the basal portion of the tree trunks. The predictions obtained with the Mixed Modified Logistic Model had, in the three portions of the shaft, few accurate errors with bias and underestimated, regardless of the diameter of the trees. Môra (2015) assessed the residuals of the respective partial volumes obtained with the $5^{\text {th }}$ degree polynomial and found, in general, similar results to this study. The volume up to $25 \%$ of the total height for trees with $\mathrm{DBH}<20 \mathrm{~cm}$ was overestimated and the larger ones had constant residual distribution regardless of the $\mathrm{DBH}$. Intermediate and upper portions behaved similarly to the ones observed in Figure 1 (A) and 1 (B). Silva et al. (2011) verified the accuracy of the diameter estimates along the trunk and the total volume for Pinus caribaea and found that the $5^{\text {th }}$ degree polynomial was again one of the most accurate equations to produce these estimates.

\section{CONCLUSION}

According to the obtained results, it can be inferred that the mixed modeling seems to have potential. However, in this study, the estimates obtained with the $5^{\text {th }}$ degree polynomial for partial volumes were better regarding those obtained with the Mixed Modified Logistical Model.

\section{ACKNOWLEDGEMENTS}

We would like to express our gratitude to Florestal Gateados for allowing access to their areas for the study's development.

\section{SUBMISSION STATUS}

Received: 17 Mar., 2017

Accepted: 7 Nov., 2018

\section{CORRESPONDENCE TO}

\section{Marcos Felipe Nicoletti}

Universidade do Estado de Santa Catarina

(Udesc), Departamento de Engenharia Florestal,

Av. Luiz de Camões, 2090, CEP 88520-000, Lages,

SC, Brasil

e-mail: marcos.nicoletti@udesc.br

\section{REFERENCES}

Arias-Rodil M, Castedo-Dorado F, Cámara-Obregón A, Diéguez-Aranda U. Fitting and calibrating a multilevel mixed-effects stem taper model for maritime pine in NW Spain. PLoS One 2015; 10(12): e0143521. 10.1371/ journal.pone. 0143521

Arias-Rodil M, Castedo-Dorado F, Cámara-Obregón A, Diéguez-Aranda U. Correction: fitting and calibrating a multilevel mixed-effects stem taper model for maritime pine in NW Spain. PLoS One 2016; 11(3): e0151297. 10.1371/journal.pone.0151297

Calegario N. Modeling Eucalyptus stand growth based on linear and nonlinear mixed-effects models [thesis]. Athens: University of Georgia; 2002.

Calegario N, Daniels RE, Maestri R, Neiva R. Modeling dominant height growth based on nonlinear mixed-effects model: a clonal Eucalyptus plantation case study. Forest Ecology and Management 2005; 204(1): 11-20. 10.1016/j. foreco.2004.07.051

Carvalho SPC, Rodriguez LCE, Calegario N, Savian TV, Lima MP, Silva CA et al. Modelagem não linear mista para descrever o afilamento de árvores clonais de Eucalyptus sp. Scientia Forestalis 2014 [cited 2019 May 20]; 42(104): 605-614. Available from: https://bit.ly/2VKcpca

Costa EA, Finger CAG, Schneider PR, Hess AF. Função de afilamento e sortimentos de madeira para Araucaria angustifolia. Ciência Florestal 2016; 26(2): 523-533. 10.5902/1980509822753

Empresa Brasileira de Agropecuária - Embrapa. Zoneamento ecológico para plantios florestais no estado de Santa Catarina. 1988 [cited 2019 May 20]. Available from: https://bit.ly/2waoMUK

Horle DC, Mendonça AR, Carvalho SPC, Calegario N. Modelagem não-linear do perfil longitudinal de fustes de Pinus oocarpa. Cerne 2010; 16(2): 177-184. 10.1590/ S0104-77602010000200009

Machado AS, Figueiredo Filho A. Dendrometria. 2. ed. Guarapuava: Unicentro; 2006.

Mendonça AR, Calegario N, Silva GF, Souza AL, Trugilho PF, Carvalho SPC et al. Modelagem da produção de sortimentos em povoamentos de eucalipto. Cerne 2014; 20: 587-594. 10.1590/01047760201420041366

Mendonça AR, Carvalho SPC, Calegario N. Modelos hipsométricos generalizados mistos na predição da altura de Eucalyptus sp. Cerne 2015; 21(1): 107-115. 10.1590/01047760201521011191

Mendonça AR, Silva GF, Oliveira JTS, Nogueira GS, Assis AL. Avaliação de funções de afilamento visando a otimização de fustes de Eucalyptus sp. para multiprodutos. Cerne 2007 [cited 2019 May 20]; 13(1): 71-82. Available from: https://bit.ly/2VWZYyQ 
Meng SX, Huang SM, Lieffers VJ, Nunifu T, Yang YQ. Wind speed and crown class influence the height-diameter relationship of lodgepole pine: nonlinear mixed effects modeling. Forest Ecology and Management 2008; 256(4): 570-577. 10.1016/j.foreco.2008.05.002

Môra R. Funções de afilamento de forma variável e modelagem de efeitos mistos em fustes de Pinus taeda $e$ Eucalyptus saligna [dissertation]. Curitiba: Universidade Federal do Paraná; 2015.

Pinheiro JC, Bates DM. Mixed-effects models in $S$ and S-PLUS. New York: Springer-Verlag; 2000.

Pires LM, Calegario N. Ajuste de modelos estocásticos lineares e não lineares para a descrição do perfil longitudinal de árvores. Revista Árvore 2007; 31(5): 845852. 10.1590/S0100-67622007000500008

R Development Core Team. The R Project for Statistical Computing [software]. 2015 [cited 2019 May 20]. Available from: https://bit.ly/19WExR5

Santos J. Análise de modelos de regressão para estimar a fitomassa da floresta tropical úmida de terra-firme da Amazônia brasileira [dissertation]. Viçosa: Universidade Federal de Viçosa; 1996.

Schöepfer W. Automatisierung des Massen, Sorten and Wertberechnung stenender Waldbestände Schriftenreihe Bad. Berlin: Wurtt-Forstl; 1966.

Scolforo JRS. Biometria florestal: parte I: modelos de regressão linear e não linear; parte II: modelos para relação hipsométrica, volume, afilamento e peso de matéria seca. Lavras: Ufla; 2005.

Silva F, Dalla Corte AP, Sanquetta CR. Equações de afilamento para descrever o volume total do fuste de Pinus caribaea var. hondurensis na região do Triângulo Mineiro. Scientia Forestalis 2011 [cited 2019 May 20]; 39(91): 367-376. Available from: https://bit.ly/2HPjaop

Souza CAM, Finger CAG, Schneider PR, Silva GF, Thomas C. Eficiência de um modelo de afilamento ajustado sem e com estratificação por classe de quociente de forma para formação dos sortimentos de Pinus taeda L. Ciência Florestal 2012; 22(1): 125-135. 10.5902/198050985085

Souza GS. Introdução aos modelos de regressão linear e não-linear. Brasília: Embrapa-SPI; 1998.

Téo SJ, Marcon A, Ehlers T, Bianchi JC, Peloso A, Nava PR, Costa RH. Modelos de afilamento para Pinus elliottii em diferentes idades, na região de Caçador, SC. Floresta 2013; 43(3): 439-452. 10.5380/rf.v43i3.30320

Trincado G, Vanderschaaf CL, Burkhart HE. Regional mixed-effects height-diameter models for loblolly pine (Pinus taeda L.) plantations. European Journal of Forest Research 2007; 126(2): 253-262. 10.1007/s10342-006-0141-7

Vismara ES, Mehtätalo L, Batista JLB. Linear mixed-effects models and calibration applied to volume models in two rotations of Eucalyptus grandis plantations. Canadian Journal of Forest Research 2016; 46(1): 132-141. 10.1139/ cjfr-2014-0435 